Z. Klin. Chem. Klin. Biochem.

13. Jg. 1975 , S. $355-360$

\title{
Enzymaktivitäten im Serum und Plasma von Mensch, Hund und Ratte sowie deren Veränderungen beim Aufbewahren des Blutes ${ }^{1}$ )
}

\author{
Von J. Breuer und W. Stucky \\ Medizinische Forschung und Wissenschaftliche Datenverarbeitung der E. Merck, Darmstadt
}

(Eingegangen am 1. Juli/14. Oktober 1974/17. April 1975)

Zusammenfassung: Im Serum und Plasma von Mensch, Hund und Ratte wurden die Aktivitäten folgender Enzyme gemessen: Alanin-Aminotransferase, Aspartat-Aminotransferase, alkalische Phosphatase, Lactat-Dehydrogenase und $\alpha$-Hydroxybutyrat-Dehydrogenase. Die Messung erfolgte am Enzymautomat 5010 der Firma Eppendorf unter optimierten Standardbedingungen bei $25^{\circ} \mathrm{C}$. Beim Stehen des Blutes über 2 Stunden veränderten sich im unterschicdlichen Ausmaß die Enzymaktivitäten. Dies betraf in der Hauptsache die Lactat-Dehydrogenase, $\alpha$-Hydroxybutyrat-Dehydrogenase und Aspartat-Aminotransferase im Serum der Ratte. Im Serum des Menschen und des Huncles sowie im Plasma von Mensch, Hund und Ratte war dieser Effekt nur wenig ausgeprägt.

Laborinterne Referenzbereiche folgender Enzyme wurden ermittelt: Alanin-Aminotransferase und alkalische Phosphatase im Serum von Hund und Ratte sowie der Lactat-Dehydrogenase und Aspartat-Aminotransferase im Serum des Hundes in Abhängigkeit von Alter und Geschlecht. Vergleichend hierzu wurden diese Bereiche auch bei einem kleineren Kollektiv von Menschen festgelegt. Die Verteilungsform der gemessenen Werte wurde geprüft.

Enzyme-activities in serum and plasma of man, dog and rat, and the variation of these enzyme activitics during storage of the blood

Summary: The following enzymes were determined in the serum and plasma of man, dog and rat: alanine aminotransferase, aspartate aminotransferase, alkaline phosphatase, lactate dehydrogenase and $\alpha$-hydroxybutyrate dehydrogenase. The enzyme assays were performed on an Eppendorf-Enzymautomat 5010 using optimised conditions at $25^{\circ} \mathrm{C}$. The enzyme-activities changed by variable amounts during standing of the blood. This concerned mainly lactate dehydrogenase, $\alpha$-hydroxybutyrate dehydrogenase and aspartate aminotransferase in the serum of the rat. In human serum and in dog serum, and in the plasma of man, dog and rat this effect was only less pronounced.

The following laboratory reference ranges were determined: alanine aminotransferase and alkaline phosphatase in the serum of dog and rat, and lactate dehydrogenase and aspartate aminotransferase in the serum of dog according to age and sex. In comparison these ranges were determined in a group of healthy volunteers. The distribution of the data was examined.

\section{Einführung}

Bei toxikologischen Untersuchungen neuer Arzneimittel am Tier werden am häufigsten Ratte und Hund eingesetzt. Um bei ihnen klinisch-chemische Untersuchungen durchfuhren zu können, ist es notwendig, Normalbereiche in Abhängigkeit von Alter und Geschlecht der Tiere zu bestimmen. Weiterhin ist es wichtig, den Einfluß der Probenvorbereitung auf die zu messenden kiinisch-chemischen Parameter zu kennen. Gerade bei der Bestimmung von Enzymaktivitäten im Serum ist be-

1) Auszugsweise vorgetragen von J. Breucr auf der Tagung Biochemische Analytik 74, 22.-26. A pril 1974 in München. kannt $(1,2,3)$, daß sich diese Parameter während der Gerinnung des Blutes zum Teil stark veründern.

Im folgenden berichten wir über die Messung der Aktivitäten der Alanin-Aminotransferase (EC 2.6.1.2), der Aspartat-Aminotransferase (EC 2.6.1.1), der alkalischen Phosphatase (EC 3.1.3.1), der Lactat-Dehydrogenase (EC 1.1.1.27) sowie der $\alpha$-Hydroxybutyrat-Dehydrogenase unter optimierten Standard-Bedingungen bei $25^{\circ} \mathrm{C}(4,5)$ im Serum und Plasma von Mensch, Hund und Ratte. Dabei wurde besonders die Beeinflussung der Meßwerte durch das Aufbewahren von Blut nit und ohne Zusatz von Heparin untersucht. 


\section{Methodik}

\section{Untersuchte Personen}

Die untersuchten Personen waren männliche Mitarbeiter (20-47 Jahre) und weibliche Mitarbeiter (19-37 Jahre) der Firma E. Merck, die frei von erkennbaren Krankheiten waren.

\section{Hunde}

Die Hunde waren männliche und weibliche Beagle-Hunde, die aus der Zucht der Firma E. Merck stammten. Sie wurden in Einzelboxen gehalten und mit Altromin-H der Firma Altromin $\mathrm{GmbH}$. (Lage/Lippe) ernährt. Sie bekamen $400 \mathrm{~g}$ Futter/Tag und Wasser ad libitum. Die Tiere standen nicht im Versuch und waren frei von erkennbaren Krankheiten.

\section{Ratten}

Die untersuchten Ratten waren Wistar-Ratten vom Stamme AF/HAN-EMD. Sie entstammten der Zucht der Firma E. Merck und waren unter SPF (specific-pathogen-free)-Bedingungen gezüchtet worden. Die Ratten wurden mit Altromin-R-Pellets der Firma Altromin GmbH. (Lage/Lippe) und Wasser ad libitum ernährt.

Die eingesetzten Ratten wurden zum Teil unter SPF-Bedingungen und zum Teil konventionell gehalten. Bei der Auswertung der Ergebnisse wurde zwischen den beiden Gruppen nicht unterschieden.

\section{Blutentnahme}

Die Blutentnahme erfolgte bei Mensch und Tier morgens zwischen $8^{00}-9^{00}$ Uhr nach mindestens 12-stündiger Nahrungskarenz. Beim Menschen wurde das Blut aus einer Vene des Armes, beim Hund aus einer Vene des Halses und bei der Ratte aus dem retroorbitalen Venenplexus entnommen.

\section{Gewinnung von Serum und Plasma}

Das Serum wurde durch 10-minütige Zentrifugation des Blutes bei $3000 \mathrm{~g}$ gewonnen. Bis zur Zentrifugation wurde das Blut bei $22^{\circ} \mathrm{C}$ in einem Wasserbad aufbewahrt. Nach dem Abpipettieren des Serums und Plasmas erfolgte sofort die Bestimmung der Enzymaktivität.

Das Plasma wurde von Blutproben gewonnen, die mit Heparin$\mathrm{Na}, 75 \mathrm{U} / \mathrm{ml}$ Blut (Roussel-Uclaf, Paris) ungerinnbar gemacht worden waren. Die Aufarbeitung erfolgte analog der Gewinnung des Serums.

\section{Messung der Enzymaktivität}

Die Messung der Enzymaktivität erfolgte mit Hilfe des Eppendorf-Enzymautomat 5010 bei $25^{\circ} \mathrm{C}$ unter optimierten Standardbedingungen $(4,5)$. Es wurden Reagenzien der Firma

E. Merck eingesetzt: Alanin-Aminotransferase, Art. Nr. 3370; Aspartat-Aminotransferase, Art. Nr. 3369; alkalische Phosphatase, Art. Nr. 3314; Lactat-Dehydrogenase, Art. Nr. 3367; $\alpha$-Hydroxybutyrat-Dehydrogenase, Art. Nr. 3368. Die Auswertung erfolgte durch Messung des Steigungswinkels der bei der Bestimmung mit dem Analogdrucker 4414 der Firma Eppendorf aufgezeichneten Punktreihe.

\section{Ermittlung von Normalbereichen}

Als ,Normalbereich“ sollte bei dieser Untersuchung aus den erhobenen Meßwerten ein Bereich aufgestellt werden, in dem bei gleichbleibender Zusammensetzung der zu untersuchenden Menschen bzw. Tiere mit großer Wahrscheinlichkeit (95\%) höchstens ein gewisser Anteil (90\%) der in Zukunft zu beobachtenden Werte liegen sollen. Fällt ein beobachteter Meßwert dann aus diesem Bereich nach oben oder unten heraus, so soll daraus nicht geschlossen werden, daß dieser Wert pathologisch ist, sondern es soll nachgeprüft werden, ob dieser Wert tatsächlich zu Recht besteht. Da das Äußere dieses Bereiches ein Warnbereich sein soll, und da man zu möglichst wenig falsch-positiven Urteilen kommen will, werden die Grenzen dieses Bereiches. nach einem Vorschlag von Rümke \& Bezemer $(6,7)$ als entsprechende innere Konfidenzgrenzen des 5. bzw. 95. Perzentils an- gegeben. Die nicht-parametrische Bestimmung dieser Bereichsgrenzen erfolgt nach Tabellen in l.c. (7).

Diesen Bereich wollen wir, um mit anderen Definitionen von „Normalbereich" nicht in Konflikt zu kommen, im folgenden als laborinternen Referenzbereich bezeichnen. Er stimmt im übrigen - bis auf die Wahl der Sicherheitswahrscheinlichkeit mit dem in 1.c. (8) als ,,sicher normal" bezeichneten Bereich überein.

\section{Ergebnisse und Diskussion}

Im folgenden berichten wir über die Bestimmungen von Enzymaktivitäten im Serum und Plasma von Mensch, Hund und Ratte. Die Versuche dienten in der Hauptsache der Festlegung von laborinternen Referenzbereichen für die Alanin-Aminotransferase und alkalische Phosphatase im Serum des Hundes und der Ratte sowie der Aspartat-Aminotransferase und der Lactat-Dehydrogenase im Serum des Hundes. Im Vergleich dazu bestimmten wir diese Enzyme auch im Serum des Menschen. Zuvor wurde das Verhalten der Enzyme beim Stehen des Blutes untersucht.

Die Zuverlässigkeit der gemessenen Enzymaktivitạten wurde durch externe und interne Qualitätskontrollen überprüft.

Aus mehreren Arbeiten (1, 2, 3, 9-12) ist bekannt, daß einerseits ein Unterschied in den Enzymaktivitäten im Serum und Plasma von Mensch und Tier besteht, und daß andererseits die Enzymaktivität im Serum nach dem Stehen von Blut zumindest der Ratte zunimmt. Um diese Aussagen an einer größeren Anzahl von Ratten und Hunden sowie vergleichend beim Menschen zu prüfen, wurden Alanin-Aminotransferase, AspartatAminotransferase, alkalische Phosphatase, Lactat-Dehydrogenase, $\alpha$-Hydroxybutyrat-Dehydrogenase im Serum und Plasma von Mensch, Hund und Ratte gemessen, nachdem das Blut $15 \mathrm{~min}, 30 \mathrm{~min}, 60 \mathrm{~min}$ und 120 min nach Abnahme bei $22^{\circ} \mathrm{C}$ (Wasserbad) bis zum Abzentrifugieren gestanden hatte (Abb. 1 und Tab. 1). Von den Menschen und von jedem Tier wurde soviel. Blut abgenommen, daß die Messungen in derselben Blutprobe erfolgen konnten.

Aus den Werten in Tabelle 1 geht hervor, daß ein Unterschied in den Enzymaktivitäten zwischen Serum und Plasma bei allen drei Spezies besteht, und zwar - außer bei der alkalischen Phosphatase bei der Ratte und bei der Alanin-Aminotransferase - zu fast allen Zeitpunkten. Ferner kann man daraus entnehmen, daß sich die. Enzymaktivitäten im Serum und Plasma beim Stehen des Blutes aller drei Spezies ändern. Diese Unterschiede sind im Serum größer als im Plasmạ. Die Enzyme LactatDehydrogenase und $\alpha$-Hydroxybutyrat-Dehydrogenase ändern sich am stärksten, Alanin-Aminotransferase und alkalische Phosphatase am schwächsten. Die größten Differenzen finden wir im Serum der Ratte, die kleinsten im Plasma von Mensch und Hund (Tab. 1). Aus der Tatsache, daß diese Veränderung im Überstand des nicht 


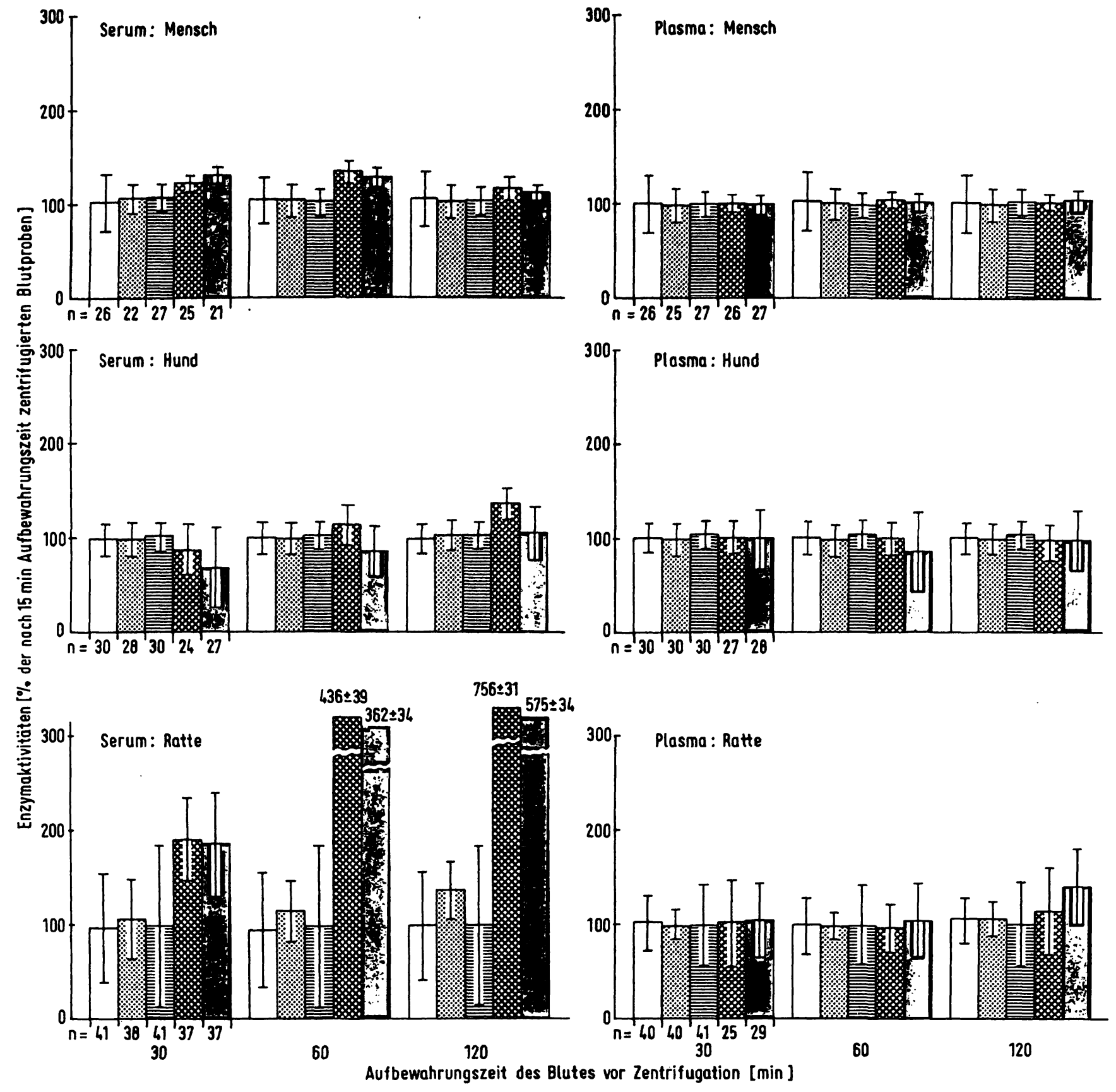

Abb. 1. Bestimmung von Enzymaktivitäten im Serum und Plasma von Mensch, Hund und Ratte in Abhängigkeit von der Zeit zwischen Abnahme des Blutes und Abzentrifugation. Die Bestimmungen erfolgten unmittelbar nach Zentrifugation unter optimierten Standardbedingungen. Weitere Einzelheiten siehc Methodik.

$\begin{array}{rlrl} & =\text { Alanin-Aminotransferase } & =\text { Aspartat-Aminotransferase } \\ & =\text { Alkalische Phosphatase } & & \text { Lactat-Dehydrogenase } \\ & =\alpha \text {-Hydroxybutyrat-Dehydrogenase } & \end{array}$

$\mathrm{n}=$ Anzahl der untersuchten Proben; die Enzymaktivitäten sind auf der Abszisse in \% der Werte, die in den nach 15 min Aufbewahrungşzeit zentrifugierten Blutproben gemessen wurden, angegeben; es sind Mittelwert und Standardabweichung graphisch dargestellt.

geronnenen Blutes weitgehend ausbleibt und auf Grund der in der Literatur $(2,3)$ wiedergegebenen Argumente dürfte kein Zweifel bestehen, daß die fast immer erhöhten Enzymaktivitäten deshalb gemessen werden, weil während der Gerinnung Enzyme aus den Thrombocyten austreten. Dies trifft sicher auch für die Aspartat-Amino- transferase im Serum der Ratte zu. Auf Grund dieser Tatsache ist die Messung dieser drei Enzyme im Serum der Ratte diagnostisch wertlos. Aus den Messungen geht klar hervor, daß man Enzymaktivitäten im Plasma messen sollte. Ähnlich ist es mit der Messung der LactatDehydrogenase im Serum des Hundes, wenn man das 
Tab. 1. Enzymaktivitäten im Serum und Plasma von Mensch, Hund und Ratte in Abhängigkeit von der Zeit zwischen Gewinnung des Blutes und Abzentrifugation. Weitere Angaben siehe Methodik.

\begin{tabular}{|c|c|c|c|c|c|c|c|}
\hline Species & Material & Zeitpunkt & $\begin{array}{l}\text { Alanin-Amino- } \\
\text { transferase } \\
{[\mathrm{U} / 1]}\end{array}$ & $\begin{array}{l}\text { Aspartat-Amino- } \\
\text { transferase } \\
{[\mathrm{U} / \mathrm{l}]}\end{array}$ & $\begin{array}{l}\text { alkalische } \\
\text { Phosphatase } \\
{[U / 1]}\end{array}$ & $\begin{array}{l}\text { Lactat- } \\
\text { Dehydrogenase } \\
{[\mathrm{U} / 1]}\end{array}$ & $\begin{array}{l}\alpha \text {-Hydroxybutyrat- } \\
\text { Dehydrogenase } \\
{[\mathrm{U} / 1]}\end{array}$ \\
\hline \multirow[t]{2}{*}{ Mensch } & Serum & $\begin{array}{r}15 \mathrm{~min} \\
30 \mathrm{~min} \\
60 \mathrm{~min} \\
120 \mathrm{~min}\end{array}$ & $\begin{array}{l}n=26 \\
16,4 \pm 10,1 \\
16,8 \pm 10,1 \\
17,2 \pm 10,2 \\
17,3 \pm 10,2\end{array}$ & $\begin{array}{l}n=22 \\
12,3 \pm 4,3 \\
12,8 \pm 5,0 \\
12,9 \pm 4,4 \\
12,6 \pm 4,3\end{array}$ & $\begin{array}{l}n=27 \\
82,6 \pm 21,2 \\
86,4 \pm 23,4 \\
85,5 \pm 23,4 \\
85,7 \pm 24,0\end{array}$ & $\begin{array}{l}n=25 \\
113,4 \pm 24,7 \\
140,4 \pm 22,6 \\
153,4 \pm 34,1 \\
153,0 \pm 31,8\end{array}$ & $\begin{array}{l}\mathrm{n}=21 \\
75,4 \pm 18,8 \\
91,4 \pm 14,8 \\
97,5 \pm 12,9 \\
85,1 \pm 12,9\end{array}$ \\
\hline & Plasma & $\begin{array}{l}15 \mathrm{~min} \\
30 \mathrm{~min} \\
60 \mathrm{~min} \\
120 \mathrm{~min}\end{array}$ & $\begin{array}{l}n=26 \\
16,1 \pm 10,2 \\
16,4 \pm 10,0 \\
16,7 \pm 10,1 \\
16,9 \pm 10,3\end{array}$ & $\begin{array}{l}\mathrm{n}=25 \\
11,8 \pm 4,2 \\
11,6 \pm 4,0 \\
12,0 \pm 4,0 \\
12,0 \pm 4,0\end{array}$ & $\begin{array}{l}n=27 \\
82,8 \pm 21,0 \\
82,9 \pm 21,6 \\
82,6 \pm 21,7 \\
85,7 \pm 22,2\end{array}$ & $\begin{array}{l}\mathrm{n}=26 \\
115,4 \pm 20,7 \\
116,3 \pm 21,3 \\
121,3 \pm 19,4 \\
117,5 \pm 18,4\end{array}$ & $\begin{array}{c}\mathrm{n}=27 \\
77,3 \pm 15,7 \\
77,3 \pm 15,8 \\
79,2 \pm 13,5 \\
81,3 \pm 17,1\end{array}$ \\
\hline \multirow[t]{2}{*}{ Hund } & Serum & $\begin{array}{r}15 \mathrm{~min} \\
30 \mathrm{~min} \\
60 \mathrm{~min} \\
120 \mathrm{~min}\end{array}$ & $\begin{array}{l}n=30 \\
28,5 \pm 9,0 \\
28,4 \pm 9,0 \\
28,4 \pm 9,3 \\
28,1 \pm 8,6\end{array}$ & $\begin{array}{l}\mathrm{n}=28 \\
22,4 \pm 7,6 \\
22,2 \pm 7,6 \\
22,1 \pm 7,2 \\
22,9 \pm 7,0\end{array}$ & $\begin{array}{l}n=30 \\
133,9 \pm 36,2 \\
136,7 \pm 41,3 \\
136,7 \pm 39,7 \\
136,8 \pm 39,4\end{array}$ & $\begin{aligned} \mathrm{n}=24 & \\
71,8 \pm & \pm 39,1 \\
53,7 & \pm 29,2 \\
70,0 \pm & \pm 29,4 \\
84,3 & \pm 27,1\end{aligned}$ & $\begin{array}{l}\mathrm{n}=27 \\
30,1 \pm 23,0 \\
20,4 \pm 17,2 \\
25,6 \pm 14,0 \\
31,6 \pm 14,5\end{array}$ \\
\hline & Plasma & $\begin{array}{l}15 \mathrm{~min} \\
30 \mathrm{~min} \\
60 \mathrm{~min} \\
120 \mathrm{~min}\end{array}$ & $\begin{array}{l}n=30 \\
27,9 \pm 9,0 \\
28,2 \pm 8,5 \\
28,2 \pm 8,4 \\
28,2 \pm 9,1\end{array}$ & $\begin{array}{l}\mathrm{n}=30 \\
22,2 \pm 7,2 \\
21,9 \pm 7,2 \\
21,8 \pm 7,3 \\
22,0 \pm 6,8\end{array}$ & $\begin{array}{l}n=30 \\
127,6 \pm 36,9 \\
133,7 \pm 38,9 \\
133,0 \pm 40,3 \\
132,6 \pm 38,2\end{array}$ & $\begin{array}{r}n=27 \\
41,0 \pm 17,7 \\
41,1 \pm 13,3 \\
41,0 \pm 14,0 \\
40,2 \pm 13,2\end{array}$ & 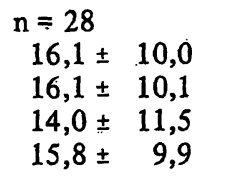 \\
\hline \multirow[t]{2}{*}{ Ratte } & Serum & $\begin{array}{r}15 \mathrm{~min} \\
30 \mathrm{~min} \\
60 \mathrm{~min} \\
120 \mathrm{~min}\end{array}$ & $\begin{array}{l}n=41 \\
18,0 \pm 11,0 \\
17,4 \pm 10,4 \\
17,2 \pm 10,7 \\
18,4 \pm 10,6\end{array}$ & $\begin{array}{l}\mathrm{n}=38 \\
58,1 \pm 23,8 \\
59,3 \pm 21,9 \\
66,6 \pm 22,5 \\
81,9 \pm 24,9\end{array}$ & $\begin{array}{l}n=41 \\
100,8 \pm 85,9 \\
100,4 \pm 89,6 \\
100,5 \pm 88,2 \\
99,9 \pm 83,5\end{array}$ & $\begin{array}{l}n=37 \\
197,5 \pm 100,0 \\
393,7 \pm 164,5 \\
903,2 \pm 313,5 \\
1452,5 \pm 470,4\end{array}$ & $\begin{array}{r}n=37 \\
74,8 \pm 54,2 \\
129,7 \pm 65,3 \\
272,0 \pm 88,5 \\
423,7 \pm 148,4\end{array}$ \\
\hline & Plasma & $\begin{array}{l}15 \mathrm{~min} \\
30 \mathrm{~min} \\
60 \mathrm{~min} \\
120 \mathrm{~min}\end{array}$ & $\begin{array}{l}\mathrm{n}=40 \\
18,0 \pm 11,1 \\
18,7 \pm 10,9 \\
18,3 \pm 10,4 \\
18,8 \pm 10,4\end{array}$ & $\begin{array}{l}\mathrm{n}=40 \\
52,6 \pm 18,0 \\
53,0 \pm 16,5 \\
53,0 \pm 16,3 \\
55,6 \pm 19,0\end{array}$ & $\begin{array}{l}\mathrm{n}=41 \\
97,2 \pm 86,2 \\
96,6 \pm 85,0 \\
97,0 \pm 85,0 \\
97,5 \pm 85,0\end{array}$ & $\begin{array}{l}\mathrm{n} \equiv 25 \\
164,0 \pm 161,0 \\
164,0 \pm 148,3 \\
173,2 \pm 150,7 \\
195,6 \pm 170,5\end{array}$ & $\begin{array}{l}\mathrm{n}=29 \\
62,3 \pm 61,9 \\
62,0 \pm 56,6 \\
64,3 \pm 55,5 \\
75,2 \pm 64,4\end{array}$ \\
\hline
\end{tabular}

Blut länger als eine Stunde bei $22^{\circ} \mathrm{C}$ stehen läßt. Aber auch dann, wenn man das Blut des Hundes möglichst bald nach der Gewinnung zentrifugiert, muß man mit größeren Schwankungen rechnen. Im Serum des Menschen erscheinen die Verhältnisse auf den ersten Blick ähnlich, da aber hier die Erhöhung der Lactat-Dehydrogenase und $\alpha$-Hydroxybutyrat-Dehydrogenase gegenüber dem 15-min-Wert bis zu $120 \mathrm{~min}$ in etwa konstant bleibt, ist eine vergleichende Aktivitätsbestimmung der Lactat-Dehydrogenase und $\alpha$-Hydroxybutyrat-Dehydrogenase im Serum des Menschen durchaus sinnvoll. Will man reproduzierbare und aussagefähigere Werte erhalten, so sollte man Enzymaktivitäten im Plasma messen. In diesem Falle ist auch eine Messung der Aspartat-Aminotransferase, Lactat-Dehydrogenase und $\alpha$-Hydroxybutyrat-Dehydrogenase im Ratten-Plasma möglich, falls man das Blut nicht länger als 60 min stehen läßt. Die Gewinnung von Plasma stößt aber bei der Ratte auf Schwierigkeiten; da das Rattenblut sehr schnell gerinnt, muß man das Antikoagulans sofort bei der Blutentnahme zugeben, was bei der Entnahme aus dem retro- orbitalen Venenplexus nur sehr schwer möglich ist. Daher kann die Bestimmung der Enzyme AspartatAminotransferase, Lactat-Dehydrogenase und $\alpha$-Hydroxybutyrat-Dehydrogenase im Plasma der Ratte nur bei einigen wenigen Versuchen durchgeführt werden. Im zweiten Teil dieser Arbeit soll die Festlegung der laborinternen Referenzbereiche der Alanin-Aminotransferase im Serum des Hundes und der Ratte, der Aspartat-Aminotransferase und Lactat-Dehydrogenase im Serum des Hundes sowie der alkalischen Phosphatase im Serum des Hundes und der Ratte in Abhängigkeit vom Alter und Geschlecht beschrieben werden. Vergleichend hierzu wurden die Enzyme auch im Serum dès Menschen bestimmt. Das Blut wurde nach mindestens 12-stündiger Nahrungskarenz den Menschen aus einer Armvene, dem Hund aus einer Halsvene sowie der Ratte aus dem retroorbitalen Venenplexus entnommen. Nach dem Gerinnen des Blutes wurde sofort zentrifugiert und das Serum in die Meßkette des Eppendorf-Enzymautomaten eingesetzt. Die Bestimmungen erfolgten unter optimierten Standardbedingungen bei $25^{\circ} \mathrm{C}$. 
Tab. 2. Laborinterne Referenzbereiche sowie mittlere Werte (Mediane) von Alanin-Aminotransferase und alkalischer Phosphatase im Serum von Mensch, Hund sowie Ratte und von Aspartat-Aminotransferase und Lactat-Dehydrogenase im Serum von Mensch sowie Hund.

Erläuterungen und Abkürzungen:

Der laborinterne Referenzbereich ist der größte, aus der Stichprobe von gegebenem Umfang ableitbare Bereich, in dem mit 95\%-iger Sicherheit höchstens 90\% der Gesamtverteilung liegen. Er ist durch Angabe seiner untcren und obcren Grenzen bestimmt.

Der mittlere Wert ist eine Schätzung für den Median (= 50\%-Wert); d. h. den Wert, oberhalb und unterhalb dessen je höchstens $50 \%$ der Gesamtverteilung liegen.

$\mathrm{J}_{\text {. }}=\mathrm{Jahre}, \mathrm{M}$. = Monate

\begin{tabular}{|c|c|c|c|c|c|c|c|}
\hline Enzym & Species & Alter & Geschlecht & Anzahl & $\begin{array}{l}\text { Laborin } \\
\text { unterer } \\
\text { Wert }\end{array}$ & $\begin{array}{l}\text { Referen } \\
\text { mittlerer } \\
\text { Wert }\end{array}$ & $\begin{array}{l}\text { rcich } \\
\text { oberer } \\
\text { Wert }\end{array}$ \\
\hline Alanin-Aminotransferase & $\begin{array}{l}\text { Mensch } \\
\text { Hund } \\
\text { Ratte }\end{array}$ & $\begin{array}{c}20-50 \mathrm{~J} \\
3-4 \mathrm{M} \\
5-8 \mathrm{M} . \\
9-12 \mathrm{M} \\
13-24 \mathrm{M} . \\
2-5 \mathrm{M} . \\
6-9 \mathrm{M} \\
10-24 \mathrm{M}\end{array}$ & $\begin{array}{l}0 \\
9 \\
0 \\
8 \\
0 \\
9 \\
0 \\
9 \\
0 \\
9 \\
0 \\
9 \\
0 \\
9 \\
0 \\
9\end{array}$ & $\begin{array}{r}136 \\
51 \\
25 \\
19 \\
221 \\
249 \\
171 \\
144 \\
39 \\
43 \\
128 \\
128 \\
97 \\
93 \\
114 \\
87\end{array}$ & $\begin{array}{r}8,0 \\
6,0 \\
11,0 \\
13,0 \\
15,0 \\
14,0 \\
17,0 \\
16,0 \\
20,0 \\
21,0 \\
18,0 \\
14,0 \\
20,0 \\
16,0 \\
16,0 \\
15,0\end{array}$ & $\begin{array}{r}11,5 \\
9,0 \\
13,0 \\
16,0 \\
21,0 \\
20,0 \\
25,0 \\
24,0 \\
27,0 \\
24,0 \\
23,0 \\
17,0 \\
25,0 \\
20,0 \\
23,0 \\
20,0\end{array}$ & $\begin{array}{l}21,0 \\
15,0 \\
29,0 \\
20,0 \\
33,0 \\
30,0 \\
36,0 \\
34,0 \\
42,0 \\
30,0 \\
30,0 \\
24,0 \\
32,0 \\
29,0 \\
35,0 \\
29,0\end{array}$ \\
\hline Aspartat-Aminotransferase & $\begin{array}{l}\text { Mensch } \\
\text { Hund }\end{array}$ & $\begin{array}{l}20-50 \mathrm{~J} \\
3-4 \mathrm{M} . \\
5-8 \mathrm{M} . \\
9-12 \mathrm{M} . \\
13-24 \mathrm{M}\end{array}$ & $\begin{array}{l}8 \\
9 \\
0 \\
9 \\
0 \\
8 \\
8 \\
9 \\
0 \\
8\end{array}$ & $\begin{array}{r}149 \\
54 \\
25 \\
19 \\
222 \\
254 \\
175 \\
144 \\
44 \\
43\end{array}$ & $\begin{array}{r}8,0 \\
7,0 \\
10,0 \\
13,0 \\
10,0 \\
10,0 \\
11,0 \\
11,0 \\
11,0 \\
11,0\end{array}$ & $\begin{array}{l}11,0 \\
10,0 \\
13,0 \\
15,0 \\
13,0 \\
15,0 \\
15,0 \\
15,0 \\
14,5 \\
16,0\end{array}$ & $\begin{array}{l}16,0 \\
13,0 \\
16,0 \\
18,0 \\
20,0 \\
20,0 \\
22,0 \\
22,0 \\
20,0 \\
21,0\end{array}$ \\
\hline Lactat-Dehydrogenase & $\begin{array}{l}\text { Mensch } \\
\text { Hund }\end{array}$ & $\begin{array}{l}20-50 \mathrm{~J} . \\
3-4 \mathrm{M} . \\
5-8 \mathrm{M} . \\
9-12 \mathrm{M} . \\
13-24 \mathrm{M} .\end{array}$ & $\begin{array}{l}0 \\
\$ \\
0 \\
\$ \\
0 \\
\$ \\
0 \\
\$ \\
0 \\
q\end{array}$ & $\begin{array}{r}149 \\
55 \\
25 \\
19 \\
199 \\
199 \\
138 \\
121 \\
36 \\
37\end{array}$ & $\begin{array}{l}95,0 \\
88,0 \\
30,0 \\
88,0 \\
28,0 \\
34,0 \\
30,0 \\
40,0 \\
38,0 \\
42,0\end{array}$ & $\begin{array}{r}130,0 \\
115,0 \\
60,0 \\
158,0 \\
62,0 \\
65,0 \\
74,0 \\
70,0 \\
67,5 \\
70,0\end{array}$ & $\begin{array}{r}180,0 \\
158,0 \\
98,0 \\
286,0 \\
150,0 \\
133,0 \\
153,0 \\
150,0 \\
140,0 \\
131,0\end{array}$ \\
\hline alkalische Phosphatase & $\begin{array}{l}\text { Mensch } \\
\text { Hund } \\
\text { Ratte }\end{array}$ & $\begin{array}{l}20-50 \mathrm{~J} . \\
3-4 \mathrm{M} . \\
5-8 \mathrm{M} . \\
9-12 \mathrm{M} . \\
13-24 \mathrm{M} . \\
2-3 \mathrm{M} . \\
4-5 \mathrm{M} . \\
6-7 \mathrm{M} . \\
8-9 \mathrm{M} . \\
10-24 \mathrm{M} .\end{array}$ & $\begin{array}{l}0 \\
8 \\
8 \\
9 \\
0 \\
8 \\
0 \\
9 \\
0 \\
8 \\
8 \\
9 \\
8 \\
9 \\
0 \\
9 \\
8 \\
9 \\
0 \\
9\end{array}$ & $\begin{array}{r}148 \\
54 \\
24 \\
19 \\
222 \\
249 \\
175 \\
144 \\
44 \\
43 \\
69 \\
69 \\
59 \\
59 \\
51 \\
49 \\
49 \\
44 \\
115 \\
88\end{array}$ & $\begin{array}{r}59,0 \\
59,0 \\
160,0 \\
155,0 \\
98,0 \\
88,0 \\
59,0 \\
58,0 \\
52,0 \\
52,0 \\
135,0 \\
62,0 \\
85,0 \\
35,0 \\
68,0 \\
26,0 \\
77,0 \\
30,0 \\
54,0 \\
20,0\end{array}$ & $\begin{array}{r}88,0 \\
66,0 \\
197,5 \\
192,0 \\
145,5 \\
147,0 \\
102,0 \\
93,0 \\
88,5 \\
77,0 \\
182,0 \\
93,0 \\
105,0 \\
48,0 \\
82,0 \\
40,0 \\
105,0 \\
40,0 \\
84,0 \\
31,0\end{array}$ & $\begin{array}{r}138,0 \\
100,0 \\
235,0 \\
210,0 \\
230,0 \\
235,0 \\
171,0 \\
147,0 \\
132,0 \\
160,0 \\
302,0 \\
141,0 \\
147,0 \\
78,0 \\
119,0 \\
50,0 \\
136,0 \\
55,0 \\
127,0 \\
45,0\end{array}$ \\
\hline
\end{tabular}


Da Angaben über die Verteilungsform der untersuchten Parameter in der Literatur nicht eindeutig sind (meist wird Normalverteilung oder logarithmische Normalverteilung angenommen), wurde - bei genügend großem Stichprobenumfang - zunächst geprüft, ob Normaloder logarithmische Normalverteilung vorliegen kann. $\mathrm{Da}$ aber relativ häufig beide Verteilungsformen abgelehnt wurden, wurden zusätzlich andere, zur gleichen Klasse gehörige Verteilungsformen überpiüt: Normalverteilung nach Verschiebung $\mathrm{z}=\mathrm{x}$-a und anschließender Transformation resp. $\log \mathrm{z}, \sqrt{\mathrm{z}}, 1 / \sqrt{\mathrm{z}}, 1 / \mathrm{z}, \mathrm{z}^{2}, 1 / \mathrm{z}^{2}$; alle diese Transformationen sind Sonderfälle einer von Box \& Cox (13) beschriebenen 2-parametrischen Schar von stetigen monotonen Transformationen. (Iterationen solcher Transformationen, z. B. $\log \log \mathrm{x}$ oder $\log \sqrt{\mathrm{x}}$, wurden nicht untersucht.)

Es zeigte sich, daß in vielen Fällen eine Vielzahl dieser Verteilungsformen auf dem 10\%-Niveau nicht abgelehnt werden konnten. Da auf Grund der vorliegenden Anzahlen nicht systematisch eine bestimmte Verteilungsform für beide Geschlechter und alle Altersgruppen eines Parameters als gültig ausgewählt werden konnte, wurden alle laborinternen Referenzbereiche mit Hilfe der Tabellen in 1.c. (7) nicht -parametrisch bestimmt. In Tabelle 2 sind der mittlere Wert (Median) sowie untere und obere Grenze des laborinternen Referenzbereichs angegeben.

Die in Tabelle 2 wiedergegebenen laborinternen Referenzbereiche schwanken je nach Alter und Geschlecht des Menschen bzw. der Tiere. Bei allen Spezies liegen die Referenzbereiche der Alanin-Aminotransferase für das weibliche Geschlecht niedriger als für das männliche Geschlecht. Beim Hund fällt bei diesem Enzym auf, daß die Werte mit dem Alter kontinuierlich ansteigen. Bei der Aspartat-Aminotransferase liegen die Werte für die Referenzbereiche in etwa gleich, unabhängig von Alter und Geschlecht beim Mensch sowie beim Hund. Bei der alkalischen Phosphatase sind wiederum, außer beim Hund, die Referenzbereiche für das weibliche
Geschlecht durchweg bedeutend niedriger als für das männliche Geschlecht. Beim Hund und besonders bei der Ratte werden die Werte mit zunehmendem Alter kleiner. Bei der Lactat-Dehydrogenase ist auffällig, daß bei den 3-4 Monate alten Hunden die Werte für die weiblichen Tiere fast dreimal so hoch sind wie fur die männlichen Tiere. Hierbei ist aber zu berïcksichtigen, daß nur 19 weibliche Tiere untersucht werden konnten.

Alle Tiere waren frei von klinischen und klinisch-chemischen Zeichen einer Krankheit. Die Fütterung und Haltung der Tiere war während der ganzen Versuchsdauer konstant, so daß hier weitgehend Gewähr für „Normalität" gegeben war, zumal keins der Tiere im Versuch stand. Allerdings ist die Gewichtigkeit der Werte in den einzelnen Gruppen durchaus unterschiedlich, da die Anzahl der Tiere sehr streute. So konnten bei den weiblichen Hunden der Altersgruppe 3-4 Monate nur 19 Tiere, dagegen bei den weiblichen Tieren der Altersgruppe 5-8 Monate 254 Tiere untersucht werden. Dennoch glauben wir, daß die ermittelten Werte repräsentativen Charakter haben.

Die ermittelten laborinternen Referenzbereiche bei den 20 bis 50-jährigen Männern und Frauen, die zum Vergleich aufgestellt wurden, sind mit zwei Mängeln behaftet. Einmal ist die Auswahl der Personen relativ klein und zum anderen konnte bei der Auswahl der Individuen keine so große Sorgfalt angewandt werden, wie sie für die Aufstellung von Normalbereichen notwendig gewesen wäre. Vergleicht man unsere Werte mit denen, die kürzlich in der Deutschen Medizinischen Wochenschrift (14) veröffentlicht wurden, so können wir aber dennoch sagen, daß das Ergebnis als Vergleichsuntersuchung durchaus zu akzeptieren ist.

\section{Danksagung}

Wir danken Frau Jutta Glaß für ihre große Mühe bei der Bestimmung der Enzymaktivitäten.

\section{Literatur}

1. Methfessel, J. \& Deml, L. (1967), dièse Z. 5, 287-291.

2. Friedel, R. \& Mattenheimer, H. (1970), Clin. Chim. Acta 30, 37-46.

3. Friedel, R. \& Mattenheimer, H. (1971), diese Z. 9, 103-106.

4. Deutsche Gesellschaft für Klinische Chemie (1970), diese Z. 8, 658-659.

5. Deutsche Gesellschaft für Klinische Chemie (1972), diese Z. 10, 182-192.

6. Rümke, C. L. \& Bezemer, P. D. (1972), Ned. T. Geneesk. $116,1224-1230$.

7. Rümke, C. L. \& Bezemer, P. D. (1972), Ned. T. Geneesk. $116,1559-1568$

8. Thefeld, W., Hoffmeister, H., Busch, E.-W., Koller, P. U. \& Vollmar, J. (1973), Deut. Med. Wochenschr. 98, 380-384.

9. Solbach, H. G., Engelhardt, A. \& Merten, R. C. (1962), 。 Klin. Wochenschr. 40, 1136-1139.
10. Loeb, W. F., Nagode, L. A. \& Frajola, W. J. (1966), Enzym. Biol. Clin. 7, 215-224.

11. Friedel, R. \& Trautschold, I. (1972), Fortschritte der Klinischen Chemie, Enzyme und Hormone, E. Kaiser (Hrsg.), Verlag der Wiener Medizinischen Akademie, S. $249-255$.

12. Bär, U., Friedel, R., Heine, H., Mayer, D., Ohlendorf, S., Schmidt, F. W. \& Trautschold, I. (1972/73), Enzyme 14, $133-156$.

13. Box, G. E. P. \& Cox, D. R. (1964), J. Roy. Stat. Soc., 211-243.

14. Thefeld, W., Hoffmeister, H., Busch, E.-W., Koller, P. U. \& Vollmar, J., Deut. Med. Wochenschr. (1974), 99, 343-351.

PD Dr. J. Breuer, Dr. W. Stucky E. Merck

D-6100 Darmstadt, Postfach 4119 